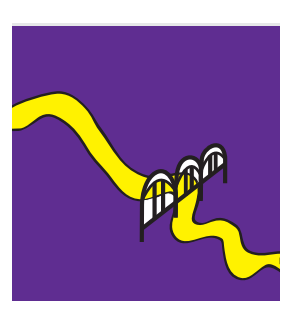

Waikato Journal

\section{of \\ Education}

ISSN 2382-0373

Website: http://wje.org.nz
Wilf Malcolm Institute

of Educational Research

Te Pütohi Rongohou Mōtourango o Wilf Malcolm

THE UNIVERSITY OF WAIKATO

\title{
Title of Issue/section: Special Issue: How to educate a nation's teachers. Debating quality initial teacher education for today and for the future
}

\section{Editor/s: Beverley Cooper, Steven Sexton, and Alexandra C. Gunn}

\section{To cite this article:}

Nelson.E., \& Johnson, L. (2017). Learning to teach in ILEs on practicum: Anchoring practices for challenging times. Waikato Journal of Education, 22(3), 63-74. doi:10.15663/wje.v22i3.374

To link to this article: $10.15663 /$ wje.v22i3.3764

To link to this volume: $10.15663 /$ wje.v22i3

\section{Copyright of articles}

Creative commons license: https://creativecommons.org/licenses/by-nc-sa/3.0/

Authors retain copyright of their publications.

Author and users are free to:

- Share - copy and redistribute the material in any medium or format

- Adapt - remix, transform, and build upon the material

The licensor cannot revoke these freedoms as long as you follow the license terms.

- Attribution-You must give appropriate credit, provide a link to the license, and indicate if changes were made. You may do so in any reasonable manner, but not in any way that suggests the licensor endorses you or your use

- NonCommercial-You may not use the material for commercial purposes.

- ShareAlike - If you remix, transform, or build upon the material, you must distribute your contributions under the same license as the original.

\section{Terms and conditions of use}

For full terms and conditions of use: http://wje.org.nz/index.php/WJE/about/editorialPolicies\#openAccessPolicy and users are free to

- Share - copy and redistribute the material in any medium or format

- $\quad$ Adapt-remix, transform, and build upon the material

The licensor cannot revoke these freedoms as long as you follow the license terms. 
Waikato Journal of Education

Te Hautaka Mātauranga o Waikato

Volume 22, Issue 3: 2017

\title{
Learning to teach in ILEs on practicum: Anchoring practices for challenging times
}

\author{
Emily Nelson and Leigh Johnson \\ Eastern Institute of Technology \\ New Zealand
}

\begin{abstract}
With fast-paced and profound change underway in schools, Innovative Learning Environments (ILEs) pose significant challenges for Initial Teacher Education (ITE) programmes also. Even within a preservice programme where preservice teachers spend two days of every week in schools and so are aware of and informally involved in ILAs, these environments and the pedagogies they require pose significant challenges for practicum preparation. In this article we report on a small-scale focus group study that explored how preservice teachers learn to teach in ILEs on practicum. We investigated how they grapple with teaching in ILEs at a time where alignment between our ITE programme and bespoke ILE developments in practicum schools is not assured. Our findings suggest that although ILEs offer preservice teachers new and unfamiliar challenges for practicum, such as orchestrating and taking responsibility for larger, more flexible groupings of learners, ILEs also offer opportunities for enhanced collaborative support and pedagogical responsibility. We also identify key anchoring practices that our preservice teachers utilise to make sense of the unfamiliar with the familiar.
\end{abstract}

\section{Keywords}

Innovative learning environments, practicum, initial teacher education, collaborative spaces, anchoring practices

\section{Introduction and background}

Coherence between ITE programmes and current schooling arrangements is promoted as an important factor in facilitating integration of new learning for preservice teachers (Deed, Cox, \& Edwards, 2014; Zeichner, 2010). However, the education sector in New Zealand is currently undergoing profound change in how teaching and learning and learning environments are conceptualised and which may have flow-on effects for ITE and coherence. Many schools are implementing ILEs, combining classes into hubs of students, and teaming teachers in collaborative teaching relationships. ITE faces an immediate challenge to stay abreast of this change in terms of what it means to teach in these transformed environments. Within our undergraduate primary teaching degree, although recent and

Wilf Malcolm Institute of Educational Research, Te Kura Toi Tangata Faculty of Education, University of Waikato, Hamilton, New Zealand

ISSN: 2382-0373

Contact details: Emily Nelson enelson@eit.ac.nz

(pp. 63-74) 
future-focused, we have found coherence elusive between our programme, and the emerging realities of practice in some of our partnership schools' ILEs. Our preservice teachers (we refer to these as candidate teachers (CTs)) experience practica in ILEs whilst our programme is underpinned largely by a conventional vision of schooling.

In this article, we consider how preservice teachers respond to this contemporary challenge whilst on practicum given that ILEs emerged in our partner schools ahead of any decisions around how to respond through our programme. Our qualitative, preliminary research explores how preservice teachers learn to teach in ILEs on practicum. It considers particularly the supports CTs identify that assist them to navigate these new spaces and the key aspects that challenge them also.

We (Emily and Leigh) practice as teacher educators within a relatively new undergraduate practicebased primary teaching degree established in 2013. Collaboratively conceptualised, designed, and enacted between a group of local principals and the ITE provider, the programme is underpinned by a foundational partnership between the tertiary provider and 26 partnership schools. CTs engage two days each week in campus classes and two days each week engaged in pre-planned 'school-based learning' tasks within one partner school facilitated by an assigned mentor teacher. An independent weekly study day enables CTs to synthesise their learning. Designed to be future-focused, especially in relation to e-learning and digital technologies, a digital competency strand threads through our degree foregrounding CT's e-learning capabilities as foundational to their skills as contemporary teachers. However, five years on, schools are radically re-visioning pedagogy and spaces, and we are challenged to respond.

In 2015, our candidate teachers first experienced practicum placements in modern learning environments (MLEs). We responded by integrating this new schooling arrangement as a focus within our Contemporary Issues course, utilising Ministry of Education materials and visits to local MLEs. In the New Zealand context, MLEs emerged through the Ministry of Education's (2011) property strategy and Statement of Intent (Ministry of Education, 2014) as a means to enact twenty-first century learning discourses with digital fluency at the core but initially emphasising property considerations. However, modern learning environments quickly morphed into innovative learning environments (Ministry of Education, n. d.) accompanied by a concomitant shift in emphasis from physical configurations to pedagogical innovation, and in 2016 our candidate teachers also experienced practicum placements in ILEs. We needed to respond more comprehensively. Compounding the challenge is the fact that most schools still organise learning and teaching within conventional singlecell classroom arrangements and where MLE, and ILEs occur, little consensus exists around the use of the terms and what these signal in the way of philosophy, physical configuration and pedagogical practices (Bradbeer et al., 2017). The bespoke way in which practice develops in these contexts also contributes to a fluid and uncertain backdrop against which candidate teachers develop their teaching practice on practicum, whilst navigating the challenge of practicum as an assessment experience.

\section{The emergence of innovative learning environments}

Innovative learning environments emerged as a response to "changing perspectives on what constitute important and appropriate education [...] in contemporary society" (Cleveland \& Fisher, 2014, p. 7) coupled with a broader societal shift from 'solid' to 'liquid' modernity (Bauman, 2000). In liquid modernity "change is too rapid for social forms to solidify, the future is unpredictable and people are expected to be flexible rather than following rules or using established knowledge" (Bauman, 2000, as cited in Webb, 2014, p. 276). This flexibility transfers to schools, entangling societal characteristics with educational practice, predicated on the assumption that schooling should more closely mirror and prepare students for contemporary workplaces and practices of the global knowledge economy (OECD, 2012).

With this liquidity and flexibility comes a need for foundational principles on which to base professional decisions; ILE development in schools has also altered what are considered foundational pedagogical principles. Teaching is now a 'team sport' (Bradbeer, 2017). ILEs shift focus from the 
learning of individuals to 'learning ecologies' (Akkerman, Bronkhorst, \& Zitter, 2011), from single cell classroom, egg crate arrangements to hubs of children working with multiple teachers to enable more responsive and flexible learning and teaching interventions. ILEs embrace the notion of ubiquitous learning, where digital technologies facilitate learning within formal and informal contexts, within and beyond schools and classrooms and across time.

Complementing this flexible vision for student learning, ILEs prioritise collaborative teaching and collective responsibility for student learning. Alterator (2017) identifies three phases that teachers pass through as they adapt to teaching in ILEs. Firstly, teachers orient to collaboration and the communication and cooperation skills involved. Secondly, a team orientation emerges where individuals prioritise the goals of the team rather than their own; and finally, teachers shift to a reflexive orientation focused on enhancing mutual agency for supporting student learning with teachers adopting the strategies and processes that support this.

In ILEs teachers, content, and resources are interlinked in new ways not common in conventional classrooms; pedagogies focus on developing twenty-first century skills and competencies; leadership is distributed and classroom practice de-privatised in favour of collaborative engagement within and beyond schools e.g., with community and online (Istance \& Kools, 2013). A commitment to fostering student ownership of learning and student agency also characterises practice (Dumont, Istance, \& Benavides, 2012; Osborne, 2013). These shifts towards flexible, student-centred learning and teaching with accompanying increases in the pace and responsiveness of decision-making for teachers leads some to argue that teaching is becoming more complex (Alterator \& Deed, 2013). For instance, a shift from planning for and managing relatively stable groups of learners within a bounded class to managing flexible groupings of learners from within three or more home groups alters the orchestration challenges for teachers (Munoz-Cristobal et al., 2015); that is, creating and conducting practice within educationally complex environments. The orchestration challenges, along with changes in the rhythmical practices (Monahan, 2000) in ILEs these generate, foreground teachers' abilities to collaborate and coordinate with other teachers and within the virtual spaces created by ubiquitous integration of technology.

Spatial types emerging in ILE developments to support a shift to learning ecologies can be characterised broadly along a continuum in terms of group size and degree of interaction (Dovey \& Fisher, 2014). Type A spatial types resemble conventional single-cell classrooms. Type B spaces describe a series of classrooms linked by a common 'street-space', allowing limited interaction between groups of students and teachers. Spaces that open up for flexible interaction within Type C spaces are characterised by convertible, flexible walls, and breakout spaces. Type D spaces extend this convertibility further by linking the flexible spaces created by street-spaces, and, finally, Type E spaces provide a dedicated commons and most comprehensively embrace the notion of open-plan. However, within this continuum of spatial types, ILEs emerge in bespoke ways in individual schools to align with particular school visions, creating a complex backdrop for teaching practice.

\section{Innovative learning environments and practicum}

Despite an explicit push towards ILEs as a schooling type in New Zealand, the literature around ILEs and initial teacher education is sparse and literature on preparing preservice teachers for practicum in ILEs even more so. Explicit policy also promotes increased ICT competence within initial teacher education programmes (Ministry of Education, 2006; Rizza, 2011) with more recent strategic priorities identifying a need for preservice teachers to understand the "pedagogy of digital learning" (New Zealand House of Representatives Education and Science Committee, 2012, p. 21) as part of their preparation for contemporary learning environments.

With research emerging on how teachers negotiate new spatial arrangements of schooling (Alterator \& Deed, 2013; Smardon, Charteris, \& Nelson, 2015), there is little focus on how student teachers navigate these same spaces. Ryan (2011) notes that "pre-service teachers are expected to make the connections between often-contradictory spaces with little or no guidance on how to negotiate such 
complex relationships" (p. 881). Benade (2016) has begun to look at creating coherence between tertiary teaching and learning spaces and ILE configurations, but found that even once alignment between environments is accomplished, student teachers do not necessarily respond positively to this coherence, as it can disrupt their expectations of learning and teaching within a tertiary context. Most pertinent to our study, Deed et al. (2014) explored how best to prepare preservice teachers for the challenges of open-plan contexts (four or more 'home groups' operating within an educational environment). They considered preparation measures needed to support preservice teachers' readiness to teach in open-plan contexts noting that preservice teachers are challenged to apply the concepts they are introduced to in their academic context into concrete practice on practicum in open-plan environments. Their findings indicate a need for ITE and school mentors to support preservice teachers' knowledge of pedagogy for open-plan contexts, personalised learning and teaching with digital technologies. They noted that "open-plan learning environments, technology and related pedagogies have broadened the conception of teaching and learning" (Deed et al., 2014, p. 138); that teaching has shifted from private and individualised practice towards collaboration in physical, pedagogical and virtual spaces.

A substantial body of literature exists focused on how to prepare preservice teachers to integrate technology on practicum (one of the foundational principles of ILE pedagogies) that may be extrapolated. Quantity and quality of pre-service experiences with technology are vital to how candidate teachers integrate technology into their placement teaching (Tondeur, Roblin, van Braak, Voogt, \& Prestridge, 2016). Ajayi (2009) similarly highlighted the importance of situated learning opportunities to learn how to teach with technology. Whilst gaining experience with technology is important for student teachers in their preservice education, to be most effective Tondeur et al. (2016) note this needs to be accompanied by explicit articulation of theory and links to pedagogical content knowledge. Blackmore, Bateman, O'Mara, and Loughlin (2011) concur, advocating the need to provide professional development to accompany changes in the physical spaces of ILEs.

Ryan (2011) asks the question "Do we teach [preservice teachers] how to inhabit and negotiate the difficult inter-spaces of ideological contradictions, of homespun or media-fuelled philosophy, of teacher accountability and its spawns, of deeply entrenched practices, and of the immediacy of passing the course?" (p. 882). In the case of our study, given that all our candidate teachers placed in ILEs for practicum have passed, we wondered how they adapted to learn how to teach in ILEs on practicum without substantial guidance from us. In this way, we expected the perspectives of our CTs would lead the way in informing our thinking around how to respond to the challenge of ILEs more proactively in our preservice curriculum in the absence of literature on the topic.

\section{Methodology}

We recruited participants for the study from our 2015 graduates and 2016 enrolled final-year TCs via a forum post in Moodle. CTs had to have experienced at least one practicum in an ILE or a variant (MLE, digital class) to participate in the research. Three 2015 graduates and six 2016 enrolled CTs volunteered to participate. Our sample size is small. This is indicative of the emerging nature of ILE development in our geographical area and the small class sizes of our programme. We typically begin the year with a cohort of 34 CTs. At the end of 2015 we produced 19 graduates and 17 graduates in 2016. Our research design does not allow us to generalise our findings.

We conducted two focus group interviews (Morgan, 2004) using a semi-structured interview protocol. We (Emily and Leigh) conducted the focus group interviews with the 2015 graduates and a colleague conducted the focus group interview with the enrolled students with whom we had an ongoing teaching relationship. One participant was unable to attend the focus group. We conducted an individual interview with this participant utilising the focus group interview questions as a protocol. The 45-minute focus group interviews were audio-recorded and transcribed by a professional typist. 
One main research question framed our research:

\section{'How do candidate teachers learn to teach in innovative learning environments (ILEs) on practicum?'}

We developed our focus group interview protocol around areas of practicum that included the characteristics of each ILE, approaches to planning, actual pedagogies in use, support and guidance, skills and dispositions needed to teach successfully in ILEs, pedagogies to foster student ownership, and technological capabilities required.

We analysed the data utilising a constant comparative approach (Silverman, 2005). We coded the graduate focus group interview transcript first for categories emerging from the data, and then the categories of the interview protocol. Both authors completed this process separately. Subsequently, we compared our coding and reached consensus through discussion, and justification of codes with data examples to develop a shared coding scheme. The coding scheme was then applied to the remaining focus group transcript and individual interview transcript. In each iterative application of the coding scheme, codes were refined and refinements considered against all data.

\section{Learning to teach on practicum: Supports, affordances and constraints}

We present key findings of the study in two sections: 1) supports; and 2) challenges. Before we introduce these sections we lay out the context by presenting a brief analysis of the spatial types of the ILE practicums discussed by participants. It is important to note that many of the concepts discussed by the participants in relation to an ILE practicum are relevant to a conventional practicum also. However, the participants raised these elements when asked about teaching specifically in an ILE, indicating to us that these elements were considered by them as familiar, but also qualitatively different, in the ILE context.

Participants described practicum experiences in 11 ILEs. All were renovations of existing spaces rather than new builds. Table 1 presents the spread of spatial types (Dovey \& Fisher, 2014) encountered.

Table 3. Spatial Types

\begin{tabular}{|c|l|c|}
\hline Spatial Type & \multicolumn{1}{|c|}{ Characteristics } & Number \\
\hline A & Traditional classroom & 4 \\
\hline B & Traditional classrooms + Streetspace & \\
\hline C & Convertible classrooms & 5 \\
\hline D & Convertible streetspace & 1 \\
\hline E & Dedicated commons & \\
\hline Unsure & & 1 \\
\hline
\end{tabular}

The spatial types encountered suggest a division between participants who experienced a mix of ILE foundational principles enacted within spaces designed for conventional teaching and learning (Type A) and participants who experienced a degree of convertibility and practice in their teaching spaces. However, this distinction is acknowledged as simplistic as some participants experienced more than one ILE practicum. The ILEs were all also very new with practice best characterised as "under construction'. This meant that participants could be described as entering a "finished beginning" (Barrat \& Zhang, 2009, p. iv) where the physical configurations were settled, but teachers were still learning how to occupy these configurations. 


\section{Supports}

In terms of supports for learning to teach in ILEs three themes emerged: 1) campus experiences functioned as anchoring practices helping to negotiate the unfamiliar socio-spatial expectations of an ILE, 2) participants' own theorising of ILEs and learning and teaching mediated their pedagogical decision-making and evaluation of spaces, and 3) participants engaged in multi-scale collaborative relationships beyond their direct supervisory relationship that provided support for their planning choices and self-efficacy as teachers.

\section{Support: Campus learning experiences as anchoring practices}

Participants' experiences with technology on campus appeared to support them to teach in an ILE, functioning as 'anchoring practices'.

One participant noted:

We did this in class ... I didn't really know how to learn about an app or ... utilise it in teaching, to be honest. I've used one or two that we did, but [teacher educator] showed me how they were used and how they could be utilised in a teaching context and what to do.

Similarly, it appears a 'tinkering' disposition, normalised in campus classes in relation to technology integration, functioned as another anchoring practice, offering participants' license and confidence to experiment around how they would integrate technology into their pedagogy:

I'm going to go tinker anyways, you know. When I went to go learn things specific for my teaching I knew I had to tinker and find out, and [teacher educator] had shown me that in the course, you know.

Tinkering in class - exploring the affordances of a range of digital tools - rehearsed a supportive disposition to learning to enact tech-rich pedagogy in the teaching role in the unfamiliar ILE context.

The way participants talked about digital technologies and their ILE practicum referenced back to the guidance theoretical models offered during their preservice campus learning, most particularly the SAMR model (Puentadura, 2012):

[Teacher Educator] touched on it when we did one of the courses ... the technology shouldn't just replace pen and paper and do the exact same thing, but in a different medium. It should enhance or morph the task into something deeper than what could be done without the [technology].

Digital technologies enhancing and morphing the depth of tasks functioned as an anchoring practice.

One participant asserted the importance of purpose in planning how digital tools are integrated into teaching practice. This message underpins technology use in our preservice programme:

If you then augment it so that you can do stuff on this [device] that you never could do with the paper, then it makes it worthwhile using that tool.

Augmentation and purpose were advocated by this participant also as an explicit focus for orienting future candidate teachers to teaching in an ILE:

... and maybe teachers going in, candidate teachers going in to ILEs, if they had a bit of a discussion with [teacher educators] or whoever, did a bit of work around that, to get your head around that idea.

In the absence of coherence between campus learning and ILEs, it appears that pedagogical experiences of campus learning provided anchoring practices as a scaffold for participants to navigate the unfamiliar ILE context through the familiar. 


\section{Support: Own theorising of ILEs}

Right from the outset of the practicum, CTs seemed to evaluate the degree of coherence in the ILE between space, furniture and pedagogy with their own theorising of ILEs. Indicatively, one participant noted,

The one I was in, it was in a hall, so the hall had been taken out but it was just an open plan setting. It had a couple of different level tables, bean bags, but nothing that stood out to be what is an ILE for me. It was just this bunch of furniture put into a room basically.

Participants seemed to look for congruence in the built pedagogies of ILEs. Congruence between these aspects seemed to facilitate engagement and suggest further possibility:

The one I was in was as you go in straight away, I'm thinking from a teaching point of view, to me it engaged me. It was bright, it was colourful, it was a space that you wanted to teach in and I think if you feel that and you've got that enthusiasm that's going to go through your teaching and hopefully for the kids they'll see that as well.

In contrast, incongruence created confusion:

I think it was a bit confusing to start with because the teachers were just starting to figure it out themselves and the space wasn't optimal in terms of noise and things like that 'cos it was a single cell so that was quite a lot to have that many children in there.

\section{Support: Multi-scale collaborative relationships}

Multi-scale collaborative relationships were a feature of the lived experience of ILEs on practicum that participants perceived as a support. We defined multi-scale relationships as those involving candidate teachers in an ongoing working relationship with two or more colleagues and focused on teaching and learning for a hub of learners:

Collaboration is key to success in that environment. You've got to work with the other teachers in your room and come up with ideas that are going to work together, and use each other as colleagues.

All participants noted the importance of being able to engage in collaborative relationships with more than one teacher, even when only one teacher held the associate teacher supervisory responsibility:

I planned in conjunction with both teachers that were in the classroom. So it was after school we would talk about which parts I'd be taking and which parts they'd be taking. So I had responsibility for the year fours for maths, so I'll plan just strictly for the year fours and the other teacher would have responsibility for the year threes. If it was whole class then I'll plan for whole class learning as well.

This collegial collaboration was facilitated by technology such as shared Google docs:

So if we were teaching something together we always got together and planned that together usually on Google docs that we could both see.

One participant who had experienced an ILE practicum and had taken a teaching job in an ILE as a beginning teacher advocated the collaborative collegial relationship as something all beginning teachers should experience:

Love it yeah I, I think it's something every beginning teacher should have ... when I got the job ... I was a little bit apprehensive and yes I had things of my own that I wanted to try, but actually the support and just the guidance from them has been incredible and I do think it's amazing for every beginning teacher to have that, to 
have, like it's such a big thing, every single thing you do is brand new learning it's amazing to have two people there that can actually help you.

Participants valued operating in the dynamic and evolving spatiality of ILEs, noting that collaborative multi-scale relationships boosted their confidence and helped them view themselves as a valuable part of the professional team.

\section{Challenges}

In this section we highlight two challenges emerging from the ILE context for preservice teachers: 1) occupying the teaching role in the virtual spaces of the ILEs, and 2) new orchestration challenges impacted on classroom management skills and planning to meet the needs of learners.

\section{Challenge: Occupying the teaching role in virtual spaces}

Participants referred to occupying the virtual spaces of ILEs as new to the challenge of teaching in an ILE. Although participants indicated previous experience with learning management systems in conventional practica, navigating these systems became an integral aspect of learning and teaching in the ILE context. The proprietary nature of the platforms impacted participants' access and ability to build and maintain pedagogical relationships with their students, effectively manage the class, and provide feedback and feedforward as a necessary aspect of formative practice:

I only had access to Teacher Dashboard through my teacher's laptop so I only used it in the morning to send my stuff out, 'cos it was a programme on her laptop, I didn't actually have access to it while I was teaching so I couldn't look at the children's ... to make sure that you can still monitor those children, especially at that older end of the spectrum.

Technology integration posed a layer of challenge for participants, in and amongst the other demands of interpreting ILEs and often alongside colleagues who were also feeling their way with technology:

We had, ohh what's that? Teacher dashboard? Hapar? [Interviewer: Hapara?]. It might have been that yeah [laughs] and through that you could send out documents to all the other computers and things so I had to learn to use that.

\section{Challenge: New orchestration challenges}

The New Zealand Curriculum (Ministry of Education, 2007) promotes knowing your learner and their learning needs as central aspects of effective pedagogy. Responsibility for multiple groups of learners across more than one home group in a hub challenged participants' capability to plan responsively for the learning needs of their students:

Before the practicum started, in both cases in the pre-discussion with your AT, you sort of work out what groups you would be taking for [the] duration of the time you were there, so you knew that you've got those kids to plan for in the areas of reading, writing, maths or whatever else and then plus the stuff you do as a whole hub or the whole class together. At [school] we had a three-week rotation on PE where one teacher took the same thing just three times in a row and the three home classes rotated round each teacher. So ... you just plan for the general feel of the class.

Planning for one group of learners but assuming it will be good for others contradicts assessment for learning and teaching as inquiry approaches that are promoted in The New Zealand Curriculum (Ministry of Education, 2007) and the expectations around pedagogy in our campus programme. Although as teacher educators, participants' perspectives concern us in terms of how we might support 
them to know their learners in a short space of time in order to plan and teach responsively. Participants seemed to view the benefits of collegial collaboration as outweighing the challenge of attending responsively to learners' needs.

Participants emphasised underlying similarities between planning and teaching in ILE and conventional class teaching; however, differences in how they talked about the teaching role indicated an orchestration challenge particular to ILEs:

I don't think it changes a whole lot. It's similar. It's just managing the extra bodies in the room and working to make sure everyone [students] is doing something and you're on the same page as everyone [co-teachers].

Planning needs to be for more students and teaching needs to orchestrate with the needs and intentions of a team of teachers, leading to the need to prioritise organisation. Participants recognised the challenge involved in participating in the learning ecologies and rhythmical practices of hubs:

I just felt I had to be really organised because if I didn't have my lessons prepared and my resources there, you're leaving so many students just fluffing around and that's when, I think, I had to prevent those situations, that was something I was more aware of. What do I need to do to prevent, I don't know, all the students just doing nothing for an hour?

To keep in step with the rhythm of the ILE, participants noted they needed enhanced organisation skills and dispositions of flexibility and adaptability.

Orchestration also included adapting to the pedagogical challenges posed by technology. Participants described having to liaise with associate teachers about what apps and platforms were available, the systems for maintaining these (e.g., fully charged devices), and any teaching points around the use of these to integrate into their lessons with students:

Something else that came up for me a couple of times was what do you do when the kids haven't charged it or can't find it or have misplaced it somewhere and probably haven't charged it was the biggest [issue] cause it was horrible when you ended up with ten kids trying to hang around the plugs and that just doesn't work either, you can't actually get what you need out of them when they're all the way over there because they haven't charged it. And then it was, well, do you have a second plan in place? If they don't have it and that sort of thing, so just getting her [associate teacher] help to make sure I was prepared.

Even though similar orchestration around technology would be required in a tech-rich classroom in a conventional practicum, the consequences of not attending to these elements in an ILE were identified seemingly at a greater order of magnitude in terms of disrupting the smooth running of the hub.

\section{Discussion}

What guidance do our preservice teachers offer us as teacher educators towards our challenge of creating coherence between our ITE programme and the realities of the profound schooling changes emerging in ILEs? Firstly, multi-scale collaborative relationships appear to expand ongoing support possibilities for preservice teachers on practicum as they grapple with the challenge of interpreting and teaching in an ILE practicum. Where practice in ILEs is characterised as 'de-privatised' (Istance \& Kools, 2013), distributed responsibility for supervision and support of the preservice teachers in our study also emerged. Whilst retaining a formal supervision relationship with one associate teacher, participants emphasised the benefits they gained from the opportunity to plan, explore pedagogical possibilities, and teach collaboratively with more experienced colleagues.

Participants drew on their own normative theorising of ILEs to interpret and respond to the bespoke nature of their ILE context and the philosophies they encountered. This suggests, as Ryan (2011) 
argues, it is vital that, as teacher educators, we engage with candidate teachers' theorising on ILEs in campus classes and practicum visiting if we are to ensure this theorising is informed and critical (Tondeur, et al., 2016) rather than a mix of ideological contradiction and 'home-spun philosophy'. This includes ensuring that the theorising of ILEs is part of practicum preparation on campus and an ongoing feature of preparatory and reflective dialogue between preservice and supervisory teachers during the practicum.

Where coherence between the campus programme and the practicum context is not possible due to the rate of change and the emergent nature of pedagogy in ILEs, identifying anchoring practices that contribute to alignment with ILEs supports preservice teachers to navigate the unfamiliar of ILEs with the familiar as a starting point. For example, integration of digital technologies as pedagogical tools in our programme appeared to enable participants to attend to purposeful pedagogical integration of technologies whilst on practicum (to the extent that proprietary learning management systems allow). This may be a transitional response; however, as Alterator (2017) warns, "the ambiguity and uncertainty of occupying and responding to ILEs demands shift in daily routines and understandings of teaching and learning" (para 6) and a more comprehensive re-conceptualisation of our programme will be necessary to take account of the growth in ILEs.

We concur with the findings of Deed et al. (2014) that preservice teachers need knowledge of openplan, or in our case ILE, pedagogies in their practicum preparation. However, as teaching in contemporary learning environments becomes more complex, our data indicate that practices for identifying learning needs such as 'teaching as inquiry' (Ministry of Education, 2007) do not sufficiently translate to teaching whilst navigating the orchestration challenges of ILEs for our participants. Teaching with a sound knowledge of the learner becomes a challenge when you may be responsible for the learning of a larger potential group of learners and when this responsibility is shared with more experienced colleagues. The preservice teacher arrives in the ILE with the most fledgling professional knowledge of learning progressions, assessment practices and other core content. Our findings resonate with Alterator and Deed's (2013) that due to the pace of decisionmaking increasing, and collaboration becoming the norm, in ILEs we need to strengthen preservice teachers' knowledge and capabilities in these areas as part of responding to the changing demands of teaching in ILEs. The lived experience of participants 'planning for the feel of them' and teaching one planned experience to more than one group of learners worries us as it jars with inquiry approaches to teaching. It also jars with the phases teachers pass through to adapt to teaching in ILEs. As the ILEs discussed in our study were in themselves under construction, we wonder how to develop preservice teachers' awareness of collaborative skills through all the phases of collaboration Alterator (2017) identifies. Participants did emphasise skills of cooperation and communication in describing the needs of the collaborative relationship with colleagues in the ILE practicum. The qualitatively different rhythmical orchestration experiences of 'managing extra bodies' and planning participants described also signals a need to increase our focus on orchestrating movement and management of individual learners and groups responsively within a hub of learners, in the virtual space, in consultation with colleagues and whilst attending to the rhythmical practices (Monahan, 2000) set by the collective.

\section{Concluding remarks}

The goal of this research was to identify how CTa learn to teach in innovative learning environments on practicum as a starting point for responding in our undergraduate primary teaching degree to the transformational changes underway in the primary education sector. In the time that our CTs have been encountering ILEs in a variety of forms and configurations, all have successfully passed their practicum, but the challenge is high. To succeed, our preservice teachers have to mesh with the spatiality of these practicum contexts, translating their campus learning and own understanding of learning environments and pedagogy into appropriate practice whilst being assessed. Engaging with our CTs to identify what supports and challenges them to learn to teach in ILEs on practicum has challenged many of our assumptions and attuned us to the nuances of their experiences. Where we 
expected collaborative teaching to form the central challenge of an ILE practicum, participants identified this as a significant source of support and efficacy. Where we expected inquiry approaches to teaching to provide a foundational practice that participants could transfer to the ILE context became almost unworkable given the orchestration and upscaled size of the group of learners they had to be prepared to teach. ILEs are not yet the norm in New Zealand (Bradbeer, et al., 2017) but they are on the increase and ITE programmes need to account for what these bespoke and qualitatively different environments mean for preservice teachers. We are committed to exploring through further research the anchoring practices that foster the adaptability, resilience and self-efficacy our preservice teachers need to navigate ILE practica against a practice backdrop of liquidity and change.

\section{References}

Ajayi, L. (2009). An exploration of pre-service teachers' perceptions of learning to teach while using asynchronous discussion board. Educational Technology \& Society, 12(2), 86-100.

Akkerman, S., Bronkhorst, L., \& Zitter, I. (2011). The complexity of educational design research, quality and quantity. Quality \& Quantity, 47(1), 421-439. https://doi.org/10.1007/s11135011-9527-9

Alterator, S. (2017). Emerging teacher skills in ILEs: Adaptation and shifting practice [blog post]. Available from http://www.iletc.com.au/emerging-teacher-skills-iles-adaptation-shiftingpractice/

Alterator, S., \& Deed, C. (2013). Teacher adaptation to open learning spaces. Issues in Educational Research, 23(3), 315-330.

Barrat, P., \& Zhang, Y. (2009). Optimal learning spaces: Design implications for primary schools. SCRI: Research report. Salford, England: Salford Centre for Research and Innovation.

Bauman, Z. (2000). Liquid modernity. Cambridge, England: Polity Press.

Benade, L. (2016, July). So the three of us will teach seventy students at the same time in the same space? Planning for a new undergraduate paper in a flexible learning environment. Paper presented at Teacher Education Forum of Aotearoa New Zealand (TEFANZ) Conference, Dunedin, New Zealand.

Blackmore, J., Bateman, D., O’Mara, J., \& Loughlin, J. (2011). Learning spaces literature review. Retrieved from http://www.learningspaces.edu.au/docs/learningspaces-literature-review.pdf

Bradbeer, C. (2017, August). Teacher collaboration in flexible learning environments: Rhetoric vs reality. Paper presented at Eastern Institute of Technology Primary Education Research Symposium, Taradale, New Zealand.

Bradbeer, C., Mahat, M., Byers, T., Cleveland, B., Kvan, T., \& Imms, W. (2017). The "state of play" concerning New Zealand's transition to innovative learning environments: Preliminary results from phase one of the ILETC project. Journal of Educational Leadership, Policy and Practice, 32(1), 22-38.

Cleveland, B., \& Fisher, K. (2014). The evaluation of physical learning environments: A critical review of the literature. Learning Environments Research, 17, 1-28. https://doi.org/10.1007/s10984-013-9149-3

Deed, C., Cox, P., \& Edwards, D. (2014). Preparing pre-service teachers for open-plan learning. In V. Prain, P. Cox, C. Deed, D. Edwards, C. Farrelly, M. Keeffe, ... Z. Yager (Eds.), Adapting to teaching and learning in open-plan schools (pp. 125-140). Rotterdam, The Netherlands: Sense.

Dovey, K., \& Fisher, K. (2014). Designing for adaptation: The school as socio-spatial assemblage. The Journal of Architecture, 19(1), 43-63. https://doi.org/10.1080/13602365.2014.882376

Dumont, H., Istance, D., \& Benavides, F. (Eds.) (2012). The nature of learning: Using research to inspire practice. Practitioner Guide. Paris, France: OECD.

Istance, D., \& Kools, M. (2013). Work on technology and education: Innovative learning environments as an integrating framework. European Journal of Education, 48(1), 43-57. https://doi.org/10.1111/ejed.12017 
Ministry of Education. (n.d.). Innovative learning environments. Retrieved from http://ile.education.govt.nz/\#home

Ministry of Education. (2006). E-learning action plan for schools for the years 2006-2010: Enabling the 21st century learner. Retrieved from http://elearning.tki.org.nz/Media/Files/Enablingthe-21st-century-learner-eLearning-action-plan-for-schools-2006-2010

Ministry of Education. (2007). The New Zealand curriculum: For English medium teaching and learning in Years 1-13. Wellington, New Zealand: Learning Media.

Ministry of Education. (2011). The New Zealand property strategy 2011-2021. Retrieved from https://education.govt.nz/ministry-of-education/overall-strategies-and-policies/propertystrategy/

Ministry of Education. (2014). Ministry of education statement of intent 2014-2018. Report presented to the House of Representatives. Wellington, New Zealand: Ministry of Education.

Monahan, T. (2000). Built pedagogies \& technology practices: Designing for participatory learning. In T. Cherkasky, J. Greenbaum, P. Mambrey, \& J. Pors (Eds.), Proceedings of the participatory design conference. Palo Alto, CA: CPSR. Retrieved from www.publicsurveillance.com/papers/pdc2000.pdf

Morgan, D. (2004). Focus groups. In S. Hesse-Biber \& P. Leavy (Eds.), Approaches to qualitative research (pp. 263-285). New York, NY: Oxford University Press.

Munoz-Cristobal, J., Jorrin-Abellan, I., Asensio-Perez, J., Martinez-Mones, A., Prieto, L., \& Dimitriadis, Y. (2015). Supporting teacher orchestration in ubiquitous learning environments: A study in primary education. IEEE Transactions on Learning Technologies, 8(1), 83-97. https://doi.org/10.1109/TLT.2014.2370634

New Zealand House of Representatives Education and Science Committee. (2012). Inquiry into 21st century learning environments and digital literacy. Wellington, New Zealand: New Zealand Parliament. Retrieved from https://www.parliament.nz/resource/0000243164

OECD. (2012). The nature of learning: Using research to inspire practice. Practitioner guide. Retrieved from https://www.oecd.org/edu/ceri/50300814.pdf

Osborne, M. (2013). Modern learning environments. Retrieved from http://coreed.org/legacy/sites/core-ed.org/files/Modern-Learning-Environments-v.1.pdf

Puentedura, R. (2012). The SAMR model: Background and exemplars. Retrieved from http://www.hippasus.com/rrpweblog/archives/000073.html

Rizza, C. (2011). ICT and initial teacher education: National policies. OECD Directorate for Education Working Paper No. 61. https://doi.org/10.1787/5kg57kjj5hs8-en

Ryan. M. (2011). Spaces of possibility in pre-service teacher education. British Journal of Sociology of Education, 32(6), 88-900. http://dx.doi.org/10.1080/01425692.2011.614745

Silverman, D. (2005). Doing qualitative research (2nd ed.), London, England: Sage.

Smardon, D., Charteris, J., \& Nelson, E. (2015). Shifting to learning eco-systems: Principals' and teachers' perceptions of innovative learning environments. New Zealand Journal of Teachers' Work, 12(2), 14-171.

Tondeur, J., Roblin, N., van Braak, J., Voogt, J., \& Prestridge, S. (2016). Preparing beginning teachers for technology integration in education: Ready for take-off? Technology, Pedagogy and Education, 26(2). http://dx.doi.org/10.1080/1475939X.2016.1193556

Webb, M. (2014). Pedagogy with information and communication technologies in transition. Education and Information Technologies, 19(2), 275-294. https://doi.org/10.1007/s10639012-9216-X

Zeichner, K. (2010). Rethinking the connections between campus courses and field: Experiences in college and university-based teacher education. Revista: Educação. Revista do Centro de Educação, 35(3). https://doi.org/10.1177/0022487109347671 